\title{
Exploration to Improve the Service Quality and Reduce the Power Customer Complaints
}

\author{
Jie Lu, Liyun Liu, Yun Nie and Hao Huang \\ State Grid Jiangxi Electric Power Research Institute,Jiangxi Nanchang 330096
}

Keywords: Power supply enterprise; Marketing service; Customer satisfaction; Marketing strategy

\begin{abstract}
With the reform of the national Power Grid Corp system, China's power supply enterprises are facing new opportunities and challenges. However, for a long time, it has been influenced by traditional ideas, management system, personnel quality and other factors. The power supply enterprise should not only participate in the market competition, but also face the increasing expectation of the electric power customer, and pursue higher economic benefit and good social benefit. Only by eliminating and reducing the gap between service standards, levels and customer expectations can we achieve this goal. How to improve the service quality and customer satisfaction of electric power personnel quickly, which has become an urgent problem for Changchun power supply company. Therefore, in the analysis of customer satisfaction point of the station, and actively seek business performance and quality service marketing strategy. It is of great practical significance to promote the development of electric power companies to further standardize and improve the quality of service and enhance the core competitiveness.
\end{abstract}

\section{Introduction}

With the rapid development of China's economy and the acceleration of the process of internationalization, deepening the reform of the electric power system is extremely urgent. The power supply enterprise must fundamentally change its role in the market, so it will become an important part of the market. The existence of the threat of competition in the market has shifted the focus of competition to the power customers, so the power companies must improve the economic benefits through quality service. Power supply enterprises in the future sales mechanism, should take the customer as the center, focusing on how to effectively own and control customer resources to work. Although the power supply enterprise is a public utility, but it is still a profit based national monopoly enterprises. Only to establish a good customer relationship, in order to improve customer satisfaction. The good customer relationship is based on the customer's satisfaction with the power products and services provided by the power supply enterprises.

Implementation of the power market reform in China, the power supply enterprises to change from monopoly to competition, the position and the environment also changed greatly. Enterprises must also be from the original distribution of electricity to the service-oriented business transformation. Excellent power supply service quality has a direct impact on the efficiency of electric power enterprises. Therefore, it is very important to improve the strategy of customer satisfaction research.

\section{The Structure of "Big Marketing" in Power Supply Company}

In accordance with the requirements of the national Power Grid Corp's "big marketing" system, the original company marketing department and the customer service center, the establishment of a new customer service center, is mainly responsible for the management of marketing operations. There are three departments in the center, respectively is the market and the customer service department, business department, and the electricity metering, the basic construction of "one center and three departments" business executives. Within the three departments according to the actual needs of their professional and team management respectively. Specific framework as shown in fig. $1:$ 


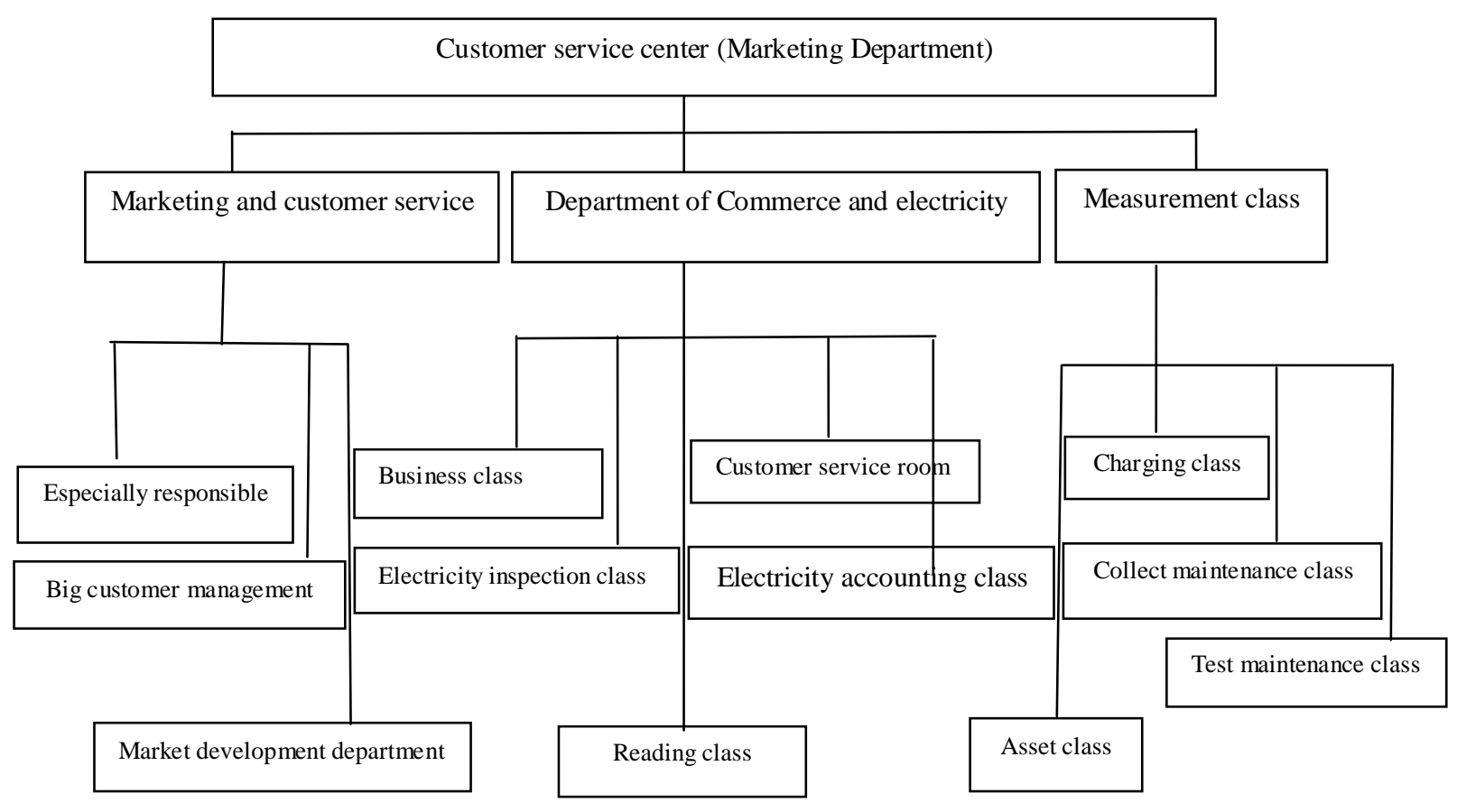

Figure 1. Organization Structure of Customer Service Center

The customer service center is directly responsible for the company's deputy general manager. The center is fully responsible for the operation and management of the city's power supply enterprise marketing services, timely reporting to the higher authorities of the completion of the indicators of marketing services, and fully implement the policy and spirit.

\section{Customer Satisfaction Problems}

Product Problem. Product quality is the lifeline of the enterprise, directly determines the economic growth of the enterprise or not. As a power supply enterprise, its product quality is also the quality of power supply, there are three main indicators: power supply reliability, voltage qualified rate, equipment reliability. Power supply reliability is the probability that the customer does not interrupt the power supply in the power supply system. Under normal circumstances, in one year as a unit, with the total number of customers uninterrupted power supply in a year and the total number of statistical period of time to express. The qualified rate of voltage is the ratio of the number of qualified voltage and the total number of sampling. Equipment reliability is the ratio of the normal operation time and the total hours of power supply equipment.

Price Problem. Standard classification is complicated with cumbersome price categories. Currently, the regional electricity price is divided into large industrial electricity, general industrial and commercial electricity, agricultural production electricity and residential electricity. The same type of electricity also needs to be classified according to the voltage level. In addition, together with the price charged, there is the Three Gorges Fund, energy support fund, city surcharge, rural net repayment fund, water funds, support funds, interest rates, etc. The classification of cost has not only increased the difficulty of electricity recovery, but also reduced customer satisfaction because it is difficult to explain to customers. It is not really based on the existing electricity market because all levels of power supply enterprises only implement the electricity price formulated by relevant government departments with no independent pricing power.

Service Problem. For a long term, the power industry has been in the state of not separating the government and businesses with short supply of power. Other units and enterprises can only follow what the "power sector" formulates, which leads to that power supply workers are blindly arrogant and there are not a few power supply workers who lack the service awareness and their service concept is not strong. They tree the majority of power customers bluntly and procrastinate at work 
with low efficiency and do not know how to empathize. They often "take kickbacks", causing great bad influence on power supply enterprises. Lagging marketing investment and technical support directly result in the backward marketing services.

\section{An Analysis of the Main Measures to Improve the Quality of Service}

Enhance Service Awareness. While faced with customers, we must first establish a "serve sincerely" awareness, especially, the front-line staffs should regard high quality service as an instinct. Power supply service personnel should always keep in mind their own words and deeds on behalf of not only their own, but on behalf of the power supply company's overall image, work full of energy, full of enthusiasm, increase the sense of active service, the State Grid Corporation of "sincere service, And seek common development "service concept into their own post practice.

Improve Standardized Services. It is necessary to strengthen the study of laws and regulations because staffs' weak awareness of legal service is the hidden dangers. At present, the awareness of the rights of customers increased, the state supervision to strengthen, which require us to master the contents of the provisions of laws and regulations, and further standardize the service procedures and work processes, all according to regulations, law, law, At the same time to strengthen the company's internal service supervision, improve the management system and assessment standards, regular organization of quality service insight unannounced visits, found that the problem in a timely manner, will not perform in place, the service is not the individual employees of the wrong behavior in the internal to correct, Power supply company standard service good social image.

Improve Power Supply Quality. To ensure safe and reliable power supply is the primary task of the power supply company to provide customers with safe and reliable power supply is an important responsibility of power supply enterprises. Improve the quality of power supply contains two aspects, one is power supply reliability, and second, power supply quality. When we cannot provide customers with safe, reliable, stable power supply, customers will be dissatisfied. Power quality is not high is one of the main factors that lead to customer complaints, in the summer high temperature, winter cold when the customer response is particularly intense. In the peak summer, peak winter electricity peak, we must be prepared in advance to predict the load, through the transformation of the line, increase the public changes in distribution, capacity, etc. to ensure the quality of residential electricity to prevent the emergence of low voltage, voltage Instability and other factors affecting the normal use of electricity voltage quality.

Improve Price Formulation Mechanism. The two-part electricity price is composed of the basic electricity price and the electricity price. The user's monthly basic electricity bill is the same, the greater the capacity, the more the basic fee per month. If the user's monthly electricity consumption is greater, then the average price of the household is smaller. Through the implementation of two-part electricity price strategy, the majority of electricity users will greatly improve the efficiency of electricity consumption, energy consumption will save a lot, help to reduce the user's additional costs. Improve the two-part pricing strategy should also consider two aspects: First, the scope of implementation should be expanded, the capacity of 100 kilowatts and above in the general business users are the implementation of two-part electricity price, the second is to reduce the price of electricity standards, so that the majority Power users enjoy the greater the amount of the lower the unit price of the preferential policies.

\section{Conclusion}

This paper introduces and analyzes the current situation of the organization of the power company, as well as three difficult problems in the process of product, price and service. According to the actual internal and external environment of the company, this paper gives an improvement strategy for these three problems. Based on the study of customer satisfaction in power supply enterprises, the following conclusions can be drawn: 1. The research on customer satisfaction of domestic power supply enterprises is still in the initial stage, many concepts are not clear, the goal is not clear. Due to the leadership of the units at all levels and employees of the service status of the 
enterprise to take the default attitude, resulting in weak service awareness of power supply enterprises, and the impact of customer satisfaction is estimated to be insufficient. 2. The development of the power supply enterprise, whether it is the consumption constraint or the supply constraint, must be carefully studied in the electricity market, adapt to the change of the market economy, and actively participate in the competition. 3 . The implementation of practical service strategies to enhance customer satisfaction plays a very big role.

\section{References}

[1] Lee H, Guillet B D, Law R. An examination of the relationship between online travel agents and hotels: a case study of choice hotels international and Expedia.com. [J]. Cornell Hospitality Quarterly, 2013, 54(1):95-107.

[2] Fishbune R J, Gilbert J, Malik N, et al. SUPPLIER DESIGN INTEGRITY ANALYTICS ENGINE AND METHODOLOGY: US20160026957[P]. 2016.

[3] Brown J L, Armstrong R W, Fee T J, et al. METHOD AND APPARATUS FOR DETECTING ARC FAULTS AND THEIR LOCATIONS IN ENCLOSED ELECTRICAL WIRING: WO/2011/090464[P]. 2011.

[4] J.Z Yang, H.Y Lin, Fault location system for underground transmission line[C]// IEEE International Symposium on Next-Generation Electronics. IEEE, 2013:157-160.

[5] Gunu U. A Consumer Focused Study of Transport Service Quality: A Case Study of Selected State Transport Corporations in Nigeria[J]. Interdisciplinary Journal of Contemporary Research in Business, 2011.

[6] M.A Liang, L.T Tao, J.K Xie, Customer demands management based on the customer portraits[J]. Power Demand Side Management, 2016.

[7] H.J Ji, A Study on the Effects of Company's Actual Response to Customer Complaints on Justice, Trust and Satisfaction[J]. 2015, 16(6):3829-3836.

[8] Hardesty T, Frank E, Freeman T, et al. Sound Preference Development and Correlation to Service Incidence Rate[C]// InterNoise. 2015.

[9] X Qin, Service quality measure of B2C company based on customer complaints[C]// International Conference on Service Systems and Service Management. IEEE, 2012:41-44.

[10] Koshollek D. Customer complaints, fewer restraints[J]. Dealernews, 2010.

[11] Sluijs J P, Larouche P and Sauter W, Cloud Computing in the EU Policy Sphere[J]. Social Science Electronic Publishing, 2011, 2011-036(1):12-32.

[12] News I, News A, News F, et al. High Point Market Announces Design Viewpoints Series Topics[J]. 2013. 